\title{
SUBJECTIVE EQUIVALENCE SCALES USING EU-SILC PANEL DATA FOR POLAND, THE CZECH REPUBLIC, AND HUNGARY*
}

\author{
Leszek MORAWSKI - Małgorzata KALBARCZYK-STĘCLIK - Rafał MIŚTA
}

(Received: 18 April 2016; revision received: 21 November 2016;

accepted: 7 December 2016)

\begin{abstract}
Equivalence scales are commonly employed in income analysis to compare the wealth of households of various compositions (e.g., 0-child, 1-child). The choice of weights for this type of analysis is not self-evident. In this paper, subjective equivalence scales for households in Poland, the Czech Republic, and Hungary are estimated. We use longitudinal EU-SILC data for 2005-2012 following the approach of Goedhart et al. (1977) as employed by Bishop et al. (2014). The use of longitudinal data shows that previous results on the subjective minimum income that were based on the OLS estimates for cross-section data overestimated the impact from current income and underestimated the role of economies of scale. Subjective equivalence scales imply a decreasing marginal cost of children in the three countries, which makes them distinct from the OECD scale. The marginal cost of a first child is similar to the values assumed in the OECD scale, but the cost of a second child is much lower.
\end{abstract}

Keywords: subjective equivalence scales, minimum income, EU-SILC, panel data, Poland, Czech Republic, Hungary

JEL classification indices: D63, I32, P46

* This work was supported by the Polish National Science Centre (NCN) under Grant No. DEC2013/09/B/HS4/01923.

Leszek Morawski, corresponding author. Professor at Vistula University and Institute of Economics, the Polish Academy of Sciences. E-mail: 1morawski15@gmail.com

Malgorzata Kalbarczyk-Stęclik, Associate Professor at the Faculty of Economic Sciences, University of Warsaw. E-mail: mkalbarczyk@wne.uw.edu.pl

Rafal Miśta, PhD student at the Robert B. Zajonc Institute for Social Studies, University of Warsaw. E-mail:rmista@wne.uw.edu.pl 


\section{INTRODUCTION}

Equivalence scales are commonly employed in income analysis to compare the positions of households of various social and economic compositions. The choice of weights for this type of analysis dates back to the end of the 19th century (e.g. Engel 1895) and is one of the oldest problems continuously discussed in economics. The question of how to compare the income of different households is vital for drawing conclusions from the analysis of poverty and income inequality. The term "equivalent income" is invoked in public debates and, therefore, provides a rationale for certain measures in economic policy. In this context, the OECD scales proposed in 1980s are most commonly cited and used.

There are several alternative methods of weighting household incomes. Most recently, Chiappori (2016) proposed to use individual preferences instead of household utilities, which eliminates many weaknesses of the traditional equivalence scales. This approach does not require the notion of family utility and does not use the comparison of utility across individuals. It is based on how much income is needed by an individual living alone, comparing to the same individual living in a family in order to reach the same indifference curve over goods and services.

Another method is subjective equivalence scales. The subjective approach uses information declared by household members with respect to how they perceive their financial situation, as opposed to the traditional approach, which is based on decision analysis and rejects declarations as a source of information (Veenhoven 2002; Schokkaert et al. 2011). The subjective approach is built around declarations about the expected minimum income or the subjective assessment of pre-determined levels of income expressed by participants in a representative household survey, which contrasts with the "revealed preference" approach prevailing in mainstream economics. The method was proposed in the 1970s, but its empirical nature, coupled with no background in the economic choice theory, made it scarcely popular with economists (e.g. Van Praag 1971; Goedhart et al. 1977; van Praag - van der Sar 1988; Kepteyn et al. 1985).

Nevertheless, declarative data, including those concerning the subjective assessment of income, started to be commonly used at the turn of the 21 st century (more in Kahneman - Krueger 2006; MacKerron 2012). Recent years have also seen some interesting papers that use subjective declarations about income to analyse equivalence scales (van Praag - Ferrer-i-Carbonell 2004; Bishop et al. 2006, 2014; Bollinger et al. 2012; de Ree et al. 2013).

Our paper draws on the method used in a recent study of Bishop et al. (2014), but it is applied to a different type of data. The results were obtained on the longitudinal data from the European Union Statistics on Income and Living Condi- 
tions (EU-SILC) survey for three countries, which have not been studied before: Poland, the Czech Republic, and Hungary. ${ }^{1}$

The subjective equivalence scales we estimated show a "reasonable" behaviour in the sense that they increase with the increase in the number of household members. At the same time, they differ from the scale calculated with the reference method. Both scales - the new one based on the longitudinal data and one from cross-section data - differ from the OECD scales commonly applied in practice. The subjective scales are lower, which suggests a larger extent of the economies of scale at the household level. They indicate a decreasing marginal cost of an additional child, while the OECD scales assume no changes in that cost.

The identification strategy assumes a log-linear relationship between the current and the declared minimum incomes, and that those with the current income above their stated minimum level overestimate the true minimum value, while those with the current income below their declared minimum income underestimate it. According to Grodner - Salas (2013), the above assumptions enable an estimation of the true (unobserved) minimum income, even though only those with the current income equal to the declared income state the correct income. However, this also means that a sample selection affected by a perception error should not significantly change the results. This conjecture prompted us to check the scales based on full samples against those obtained from observations for which the relative perception error (the ratio of the difference between a declared minimum income and disposable income to disposable income) does not exceed $25 \%$.

The remaining part of this paper describes the methods, followed by the estimation strategy and its results. A summary concludes the paper.

\section{ESTIMATION STRATEGY AND METHOD}

Equivalence scales are most commonly defined as the relation of the cost of living of a household of a given demographic composition (such as a couple with two children) to the cost of living of a reference household, which is usually a single-member household. Such a scale can be presented as:

$$
D(p, u)=\frac{C(p, u, f)}{C(p, u, r)}
$$

where $p$ is prices, identical for all households, $u$ is unobservable utilities, and $f$ and $r$ are subscripts for household categories. Adopting the method of analysis

The similar study of Bishop et al. (2014) used the same data for the euro zone countries only. 
described in Goedhart et al. (1977), we assume that the values of the C(.) function may be inferred from the declarations of minimum income $y_{\text {min }}^{*}$, which allows us to write: $y_{\text {min }}^{*}(x)=C\left(p, u_{\text {min }}^{*} x\right)$, where $x$ designates the household category and $u_{\text {min }}^{*}$ is the unobserved utility level.

In this approach, the equivalence scale is defined by assuming that households having an income on par with the declared minimum income have the same utility. Therefore, with the declarations of households with disposable income $y$ close to the minimum declared values $y_{\min }$, it is possible to estimate monotone parameters of the increasing function $y_{\text {min }}^{*}(x)=f\left(y_{\text {min }} x\right)$. Thus, the equivalence scale can be formulated as:

$$
D\left(p, u_{\text {min }}^{*}\right)=\frac{y_{\text {min }}^{*}(f)}{y_{\text {min }}^{*}(r)}=\frac{f\left(y_{\text {min }}, f\right)}{f\left(y_{\text {min }}, r\right)}
$$

In practice, the logarithmic and linear form for $f\left(y_{\text {min }} x\right)$ is most commonly adopted.

Grodner and Salas (2013) note that the model should be estimated based on observations for which the declared minimum income is close to the disposable income. However, such observations are usually too scarce to yield any statistically significant results. In such situations, following Goedhart et al. (1977), it is assumed that households having a disposable income above the minimum, overestimate the real level of such income, whereas those with an actually insufficient income underestimate that level. With this identification condition, it is possible to determine the unobserved minimum income, even if the number of observations for which the values of disposable income are close to the declared levels is small. Since the EU-SILC set provides information on a large number of observations, we decided to test how the choice of the sample size affects the equivalence scale estimates. The decision to use two samples could be linked to the discussion in Goedhart et al. (1977), who advocate using the $100 \%$ sample if a number of required observations is insufficient, and Grodner - Salas (2013), who make a case for using the smaller sample. Our estimation has been conducted on a complete set of data (the "100 sample") and on a sample limited to those observations for which the relative error does not exceed $25 \%$ (the " 25 sample").

The longitudinal data used in the study allow us to control for the existence of time-invariant, unobservable characteristics of individual households affecting the dependent variable. The existence of such effects causes the inefficiency of the OLS estimator if they are not correlated with explanatory variables, or leads to a bias of that estimator if such a correlation exists. 
The linear model assuming the existence of individual effects for the relation between the logarithm of the declared minimum income and explanatory variables is defined as follows:

$$
\ln \left(y_{i, t}^{\min }\right)=\beta_{0}+\beta_{1} \ln \left(y_{i, t}\right)+\beta_{2} z_{z_{i, t}}+\beta_{3} z_{3_{i, t}}+\ldots+\beta_{n} z_{n_{i, t}}+\left(v_{1}+u_{i, t}\right)
$$

where $v_{l}$ describes the time-invariant unobservable individual effect associated with the characteristics of a household and $u_{i, t}$ is the general random effect.

When estimating parameters $\beta_{0}, \beta_{1} \ldots, \beta_{\mathrm{n}}$ using the least squares method (the so-called pooled OLS, or POLS), we risk obtaining inconsistent parameters if individual characteristics are correlated with regressors. Additionally, the existence of fixed individual effects leads to total random errors $\left(v_{i}+u_{i, t}\right)$ for observations concerning the same household being correlated together, which results in the inefficiency of the OLS estimator. If there is no correlation between the individual effect and the explanatory variables, the random effects (RE) estimator is the effective and consistent estimator. However, when modelling income variables, it is more reasonable to assume the existence of a correlation in the empirical model, which implies the inconsistency of the RE estimator. In such a case, the consistent estimator is the fixed effects (FE) estimator obtained after the model formula is transformed into the following form:

$$
\ln \left(\dot{y}_{i, t}^{\min }\right)=\beta_{1} \ln \left(\dot{y}_{i, t}\right)+\beta_{2} \dot{z}_{i_{i, t}}+\beta_{3} \dot{z}_{z_{i, t}}+\ldots+\beta_{n} \dot{z}_{n_{i, t}}+\dot{u}_{i, t}
$$

where $\dot{y}_{i, t}^{\min }=y_{i, t}^{\min }-\bar{y}_{i}^{\min }, \dot{y}_{i, t}=y_{i, t}-\bar{y}_{i}, \dot{z}_{k}=z_{k}-\bar{z}_{k}$ for and $\dot{u}_{i, t}=u_{i, t}-\bar{u}_{i}$.

By applying this transformation, the fixêt factor is eliminated from the model as $v_{i}=u_{i, t}-\bar{u}_{i}$. Parameter estimates made using the FE method are precise enough only if the corresponding regressors are sufficiently time-variant. If their variation is only slight, then standard errors for the parameter estimates are high, which makes it difficult to extrapolate the results to observations from the outside of the sample. More to the point, the transformation of fixed effects removes not only unobservable fixed effects, but also all time-invariant regressors.

Using the FE estimator, we assume no correlation between the error and the explanatory variables, i.e. $E\left(\mathrm{X}_{\mathrm{i}, \mathrm{t}} * \mathrm{v}_{\mathrm{i}}\right)=0$, whereas for the RE estimator we additionally assume that $E\left(\mathrm{X}_{\mathrm{i}, \mathrm{t}} * \mathrm{v}_{\mathrm{i}}\right)=0$. The Wooldridge test can be used to verify whether the second of these orthogonality conditions is true, thus allowing for the selection of the correct estimation method (Wooldridge 2010). 


\section{Data}

The presented results were obtained using the longitudinal data from the EUSILC survey for 2005-2012. EU-SILC is a survey covering all EU countries and aimed at providing data on income poverty and social exclusion. The survey collects social, demographic, and income data about households and their members. In Poland, the EU-SILC survey has been run since 2005. A rotating household panel is used in the longitudinal survey (with a 4-year rotation in most participating countries).

For the three countries included in the analysis, namely Poland, the Czech Republic, and Hungary, we had a total of 640,000 observations in approximately 240,000 households. The selected countries are post-communist countries with a similar political and economic history after World War II. In 2012, the GDP at market prices as measured in PPS per inhabitant was about $60 \%$ of the EU15 average in Poland and Hungary, and it reached a level close to $75 \%$ in the Czech Republic (Table A1 in the Appendix). In each country, labour productivity is below the average for the EU15, while the shares of manufacturing and agricultural sectors in the total gross value added are above the average. On the other hand, the importance of such sectors as "public administration, defence, education, human health and social work activities" as well as "professional, scientific and technical activities; administrative" sectors is lower in the analysed group. Since the three countries are quite different from the advanced European countries, it is interesting to verify to what extent the scales for these Central European countries are consistent with those previously calculated for more advanced countries.

Also, it should be noted that the selected countries are not economically or socially identical, despite the 50 years of their common history after 1945 . The Czech Republic is the most advanced in terms of per capita GDP and labour productivity levels. The position of the Czech Republic is also confirmed by its higher HDI ranking. The countries also differed (or differ) in their family policy expenditure in the years of 2005-2012, with Hungary's spending between 3.3\%$3.5 \%$ of GDP, the Czech Republic between $1.7 \%$ and $1.8 \%$ of GDP, and Poland just between $1.06 \%$ and $1.07 \%$ (OECD 2016). Financial transfers accounted for the largest share in the overall support to families in Hungary. The Czech Republic had the smallest share of aid in the form of services, but the largest share of support in the form of tax reliefs and tax credits compared to the other two countries. According to the report published by PricewaterhouseCoopers (2015), the average public aid per child was EUR 530 in Poland, over EUR 1100 in the Czech Republic, and nearly EUR 2000 in Hungary.

The variable explained in the regression model is the declared minimum income, the value of which is derived from the question, "In your opinion, what is 
the very lowest net monthly income your household would have to have in order to make ends meet?" The income variable among the explanatory variables is the disposable income adjusted for each year and country by harmonised consumer price indices published by Eurostat. ${ }^{2}$ Observations on the extreme values of minimum income and disposable income per household member (observations in the first and last centile) were excluded from the study.

The analysis covered six types of households: a couple with one child (a2k1); a couple with two children (a2k2); and families with one to four adults and no children (a1k0 to a4k0). A child is defined according to the definition of OECD, that is, as a person below 14 years of age. The populations of the two analysed samples, i.e. the " 100 sample" and the " 25 sample", once the issue of missing data in income variables have been eliminated, are described in Tables A2 and $A 3$ in the Appendix. Data were most frequently missing in the Polish panel for 2005-2008 (between 10 and 13\% for various types of households, with the largest share for a $1 \mathrm{k} 1$ households at $17.9 \%$ ). For later panels, the issue of missing data was less common and usually did not exceed $10 \%$, although, at $16.1 \%$, the percentage was still high in the 2009-2012 panel for a1k1 households. In Hungary, the percentage of missing income data was below $10 \%$, and in the latest panel for 2009-2012, it was below 5\%. The problem of missing data was virtually non-existent in the case of the Czech Republic. Therefore, the income data can be considered satisfactory.

The most numerous households in all the countries are a $2 \mathrm{k} 0$ households. Upon limiting the sample size ("25 sample"), a1k0 households become the most numerous in the Czech Republic. They are the second most numerous in the other countries. Tables $A 4$ and $A 5$ show the percentages of households, by type, which did not change their composition between the panels. This information is vital for the ability to estimate the model using the FE estimator. Changes were the least frequent in a $1 \mathrm{k} 0$ households. Over $90 \%$ of a $1 \mathrm{k} 0$ households in all the countries continued as such for all the years of the survey. This is hardly surprising considering that they include households of single elderly persons. Changes were much more frequent in the other types of households (in the case of families with children, a $2 \mathrm{k} 1$ and a $2 \mathrm{k} 2$, between 50 and $60 \%$ of households did not change their type), and this variation can be observed in both the entire sample and the " 25 sample". Such an extent of variation makes it possible to conduct a panel analysis with fixed effects.

2 The variable used in this study is HY020 (total disposable income) comprising income from work (employment or self-employment), old age benefits, insurance benefits (survivor's benefits, sickness benefits, disability benefits), family/children-related allowances, housing allowances, and social aid (for details, see "Description of target variables: Cross-sectional and Longitudinal”, EU-SILC 065, 2011). 


\section{RESULTS}

Equation (4) was estimated using OLS and FE methods. We discuss the results of both methods since a correlation between fixed effects in time and explanatory variables was found using the Wooldridge test (Table A6), and the OLS results are presented as a proxy of more traditional results obtained from cross-sectional data. ${ }^{3}$ Three kinds of results are discussed below. The first one is derived from the fact that the income elasticities obtained from the FE estimator are smaller than those from the OLS method (Tables A7, A8). The FE values are around 0.3 for the restricted sample and 0.1 for the unrestricted one, and 0.7 and 0.4 for the OLS method. It is interesting that there is no visible country effect within any of the estimation methods. The income elasticities estimates measure the importance of the adaptation effect that was described in Goedhart et al. (1997). The role of the effect is related to the slope of the relationship between the log-minimum income and log-disposable income presented in Goedhart et al. (1997: Figure 3). A smaller slope (lower income elasticity) means faster adaption of the subjective minimum income to the true minimum value. This is a desired result since with smaller elasticities, the differences between declarations and the unobserved minimum income are smaller. Controlling for the correlation associated with the existence of fixed effects in time reveals also a stronger effect of additional members in a household on the minimum income. For instance, the semi-elasticities for an a $2 \mathrm{k} 0$ household and for a $2 \mathrm{k} 2$ are over a dozen p.p. higher for the FE estimates than for the OLS ones.

Since unobserved time-invariant variables are significant, the conclusions based on the OLS estimates overestimate the role of the current income and underestimate the economies of scale when the expected subjective minimum income is estimated. The FE method indicating a weaker role of the current income and a stronger role of the household structure seems to be more intuitively appealing. That is why we prefer the FE estimator, which suggests that subjective declarations about the minimum income are less subjective and are more objective in the sense that they are closer to the unobserved objective values than it would result from the OLS approach.

However, this result may be biased by observations with high values of the perception errors that are taken into account in the estimation. As we have mentioned

3 Bertrand et al. (2004) demonstrated that the traditionally computed values of standard deviation for the FE estimator are significantly underestimated if autocorrelation of the random factor is present. In such cases, it is proposed to use estimators that are robust to clustering and treat each observation (e.g. a household) as a separate cluster. For this reason, we apply HuberWhite estimators, which are cluster-robust (cluster-robust Huber-White standard errors). 
above, restricting the sample on the perception errors may help to overcome the negative consequences of an idiosyncratic measurement error problem. When only those observations with the relative perception error (a difference between declared minimum income and disposable income over disposable income) below $25 \%$ are included in the estimation, the values of income elasticity estimate increase. This is not surprising since the concave relationship between the current income and the declared minimum level has been assumed. However, the estimates of 0.7 for the OLS 25 models make them a bit suspicious. The results for the FE25 models - around 0.3 - are more sensible. Changing sample sizes increases income elasticities, but does not make much difference in the estimates of a household type effect. The choice between the FE25 model and the FE100 model must indeed rely on ethical considerations. If we believe that the true minimum income should be calculated only on the basis of declarations stated by those who are on the verge of subjective minimum level, than the FE 25 model should be applied. This approach can be motivated by a claim that only such people know the value of the true minimum income. If, however, we think that people whose current income is significantly different to their declared minimum amount also should be taken into consideration, the whole sample should be used. The main distinction here is whether we accept that those who are not at the verge of minimum income should decide what the minimum income is. As we can see from Figure 1, this decision influences the values of the subjective equivalence scales that appeared in poverty and income analysis (Figure 1 and Table A9).

Figure 1 presents the three most interesting subjective scales - FE25, FE100 and OLS100 - and the modified OECD scale (the values for the scales from all models together with confidence intervals are given in Table A9). The scales are reasonable - they are not decreasing with the number of household members. The differences between the expert scales (the OECD scale and the square root scale) and the subjective scales increase with the number of household members. They are the smallest for $\mathrm{a} 2 \mathrm{k} 0$ and $\mathrm{a} 2 \mathrm{k} 1$ households and the greatest for a $4 \mathrm{k} 0$ ones. The values for the OLS100 model for Poland are below those for the euro zone in Bishop et al. (2014). The values for the Czech Republic and Hungary are above that benchmark. In most cases, the differences hover around 5\%, which gives us the confidence in the meaningfulness of the discussed results.

The values for the FE100 models do not differ much from those from the OLS100 models. The only noticeable differences are in the case of a2k1 and a2k2 households in the Czech Republic and Hungary. For the Czech Republic, the scales are 1.47 for $\mathrm{a} 2 \mathrm{k} 1$ and 1.56 for $\mathrm{a} 2 \mathrm{k} 2$, with the estimates for Hungary of, respectively, 1.44 and 1.54. Larger differences are noticed after the sample restriction is added (Table A9). The differences between the OLS100 model and the OLS25 model come up to $30 \%$, meaning that limiting the sample size to those 


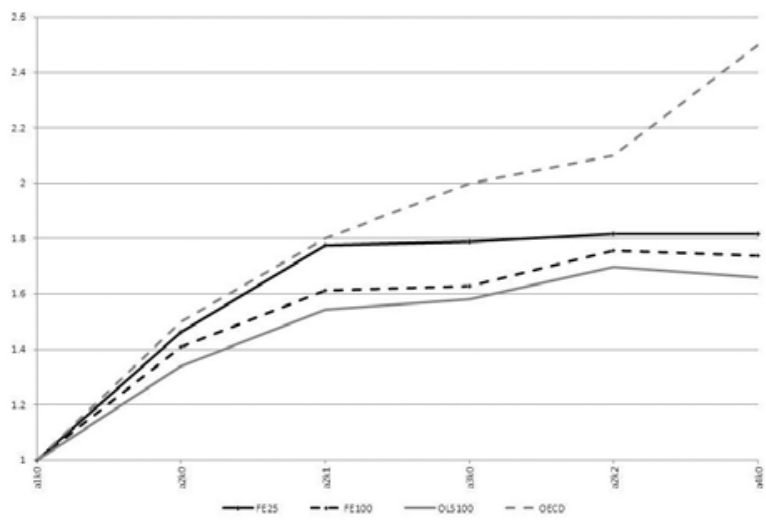

A) Poland

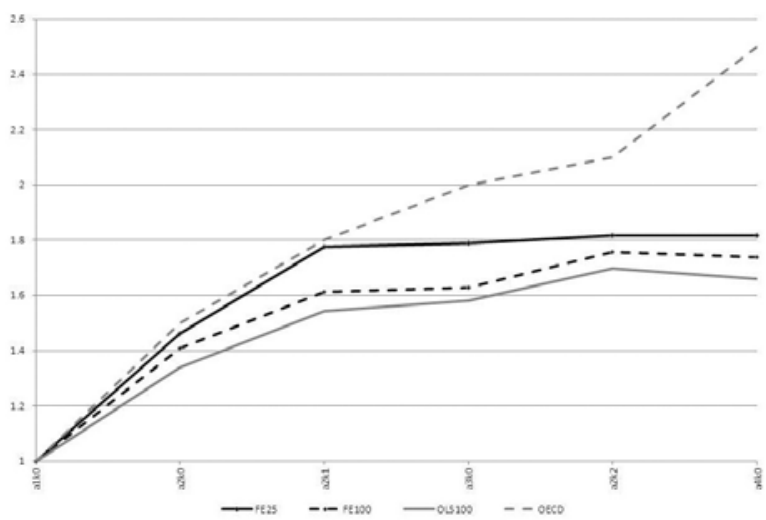

B) Czech Republic

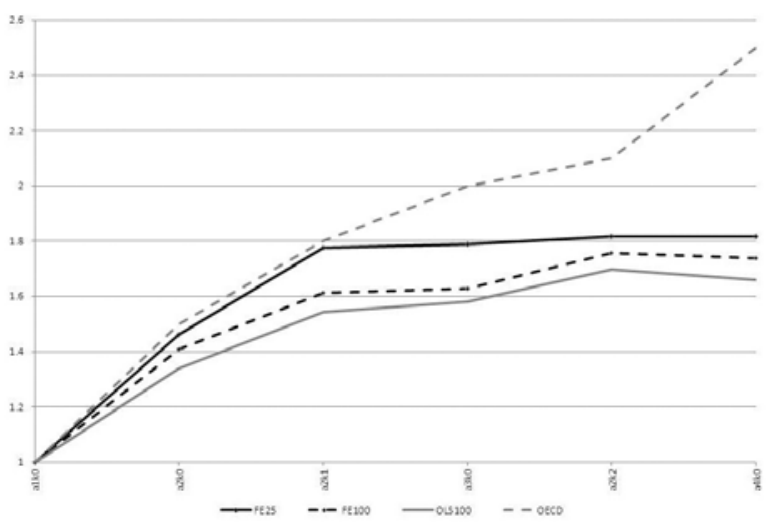

C) Hungary

Figure 1. Subjective equivalence scales for selected models

Source: Authors' calculations based on EU-SILC 2005-2012 data.

Notes: The number of observations used for calculations can be found in the Appendix, Table A7 (FE25) and Table A8 (FE100 and OLS100). 
with the disposable income close to the minimum level leads to a larger importance of the economies of scale. Implementing both changes - putting the restriction on a sample size and applying the FE estimator - increases the values of the equivalence scale by a factor of about 1.1 for Poland and for childless households (a2k0, a3k0 and a4k0) in the Czech Republic. The values for a2k1 and a2k2 households in the Czech Republic increase by a factor of about 1.03. Changes in Hungary for households with children (a2k1 and a2k2) take a different direction: the values of the scale are smaller by a factor of 0.9 . For other household types, the values rise by a factor of 1.03 .

As we see, the introduction of both changes may shift the scale in any direction from the baseline case of the OLS100 model. This happens because controlling for fixed effects decreases the values of a scale (i.e. it increases the role of economies of scale), while restricting a sample makes them larger (i.e. it decreases the role of economies of scale). It is hard to predict which effect is stronger.

Another conclusion concerns the marginal cost of children which is implied by the equivalence scales. According to Bishop et al. (2014), the additional cost caused by a first child in a couple is $30 \%$ of a cost for an alk0 household in the euro zone. The respective estimate for a second child is 0.14 . They reported the smallest value of 0.15 for the first child (the Netherlands) and the largest one of 0.60 (Ireland). Our baseline results from the OLS100 models are in line with these estimates. Our scales show a declining marginal cost of a child, which is a typical result for a subjective approach and stays in contrast with the OECD approach that assumes a constant marginal cost. Our OLS100 estimates are 0.21 for Poland, 0.33 for Hungary, and 0.36 for the Czech Republic, in each case for the first child, which makes them similar to the OECD approach with the cost of 0.3 .

The restricted FE models show smaller estimates of the marginal cost of the first child for Hungary (0.14) and the Czech Republic (0.28), and there is no change for Poland (0.31). The marginal costs decrease mostly due to the change in the estimation method. The sample selection effect is weaker. This again highlights the importance of controlling the fixed effects. The additional cost brought on by the second child is considerably lower than that of the first one. This comes as no surprise, bearing in mind the results in Bishop et al. (2014). Estimates for the OLS100 models are: 0.15 for Poland, 0.13 for the Czech Republic, and 0.11 for Hungary. Results for the FE25 cases are even lower: 0.041 for Poland, 0.08 for Hungary, and 0.09 for the Czech Republic. Such small values are consistent with the estimates in the reference paper, where we find 0.08 for Slovakia, 0.06 for Austria, and 0.07 for France. 


\section{CONCLUSION}

The OECD equivalence scales developed in the 1980s are frequently applied in social studies. However, there are interesting alternatives to this dominant approach. One of them is a subjective equivalence scale based on the declared values of minimum income. Our paper draws on this approach by presenting estimates of the subjective equivalence scales for Poland, the Czech Republic, and Hungary using the method proposed in Goedhart et al. (1977). Recently, this method was applied in Bishop et al. (2014) to estimate the subjective equivalence scale in the euro zone using cross-sectional data from the European Union Statistics on Income and Living Conditions (EU-SILC) survey.

We used the longitudinal data from the EU-SILC survey, which allowed us to control the bias resulting from the correlation of the time-invariant random factor and the current disposable income. We incorporated a discussion of the result sensitivity to sample selection based on the difference between the disposable income held and the declared minimum income. For the purpose, we used a limited sample of households for whom the said difference did not exceed $25 \%$. The objective of the analysis was to test whether the perception error affects the results of the equivalence scale estimates.

The application of the fixed effects estimator demonstrated a stronger significance of the adaptation effect, making the current income less important for the subjective minimum income. This is a much desirable result, since we would like to have the true unobserved minimum income that is treated as a measure of the cost of living to be independent from the current income situation. That is why smaller estimates of the income elasticities would be highly desirable, and it is supported by Schwarze (2003) and Knight - Gunatilaka (2012). By limiting the samples, we showed that the short-run income aspirations of households with income close to the minimum income are more sensitive to income changes than those postulated when the full sample is used.

The estimated subjective equivalence scales are different for different countries, which show that using a common OECD scale is an oversimplification. Controlling the time-invariant fixed effects and limiting the sample size reveal a smaller degree of the economies of scale in households in Poland and in the Czech Republic, and higher in Hungary. The differences between the expert scales (the OECD scale and the square root scale) and the subjective ones increase with the number of household members. The subjective marginal cost of a first child is lower than the cost of a second one, which makes the subjective scales different from the expert scales. Marginal costs are lower when we control for the fixed effects, but their levels still fall within those known from the literature. 
The comparison of the three Central European countries has revealed the differences in the size of economies of scale of a household, despite similarities in economic development and the post-war history. It seems that a more in-depth analysis linking the generosity of the social transfer system to the perceived extent of the economies of scale as well as the role of country specific cultural characteristics could be helpful in explaining these differences.

\section{REFERENCES}

Bollinger, C. - Nicoletti, C. - Pudney, S. (2012): Two can Live as Cheaply as One...But Three's a Crowd. ISER Working Paper, No. 10/2012.

Bertrand, M. - Duflo, E. - Mullainathan, S. (2004): How Much should We Trust Differences-inDifferences Estimates? Quarterly Journal of Economics, 119(1): 249-275.

Bishop, J. A. - Luo, F. - Pan, X. (2006): Economic Transition and Subjective Poverty in Urban China. Review of Income and Wealth, 52(4): 625-641.

Bishop, J. A. - Grodner, A. - Liu, H. - Ahamdanech-Zarco, I. (2014): Subjective Poverty Equivalence Scales for Euro Zone Countries. The Journal of Economic Inequality, 12(2): 265-278.

Chiappori, P. A. (2015): Equivalence versus Indifference Scales. The Economic Journal, 126(592): 523-545.

Engel, E. (1895): Die Lebenskosten Belgischer Arbeiter-Familien Früher and Jetzt. International Statistical Institute Bulletin, 9: 1-74.

Goedhart, T. - Halberstadt, V. - Kepteyn, A. - Van Praag, B. (1977): The Poverty Line: Concept and Measurement. Journal of Human Resources, 12(4): 503-520.

Grodner, A. - Salas, R. (2013): Utility Independent Subjective Poverty Line and Equivalence Scale. Presentation at the 5th ECINEQ Meeting, 22-24 July 2013, Bari.

Kahneman, D. - Krueger, A. B. (2006): Developments in the Measurement of Subjective WellBeing. Journal of Economic Perspectives, 20(1): 3-24.

Kapteyn, A. - van de Geer, S. - van de Stadt, H. (1985): The Impact of Changes in Income and Family Composition on Subjective Measures of Well-Being. In: David, M. - Smeeding, T. (eds): Horizontal Equity, Uncertainty, and Economic Well-Being. Chicago: University of Chicago Press, pp. 35-68.

Knight, J. - Gunatilaka, R. (2012): Income, Aspirations and the Hedonic Treadmill in a Poor Society. Journal of Economic Behaviour \& Organization, 82(1): 6781.

MacKerron, G. (2012): Happiness Economics from 35,000 Feet. Journal of Economic Surveys, 26(4): 705-735.

OECD (2016): Family Benefits Public Spending (Indicator).

van Praag, B. (1971): The Welfare Function of Income in Belgium: An Empirical Investigation. European Economic Review, 11(3): 337-369.

van Praag, B. - Ferrer-i-Carbonell, A. (2004): Happiness Quantified. Oxford: Oxford University Press.

van Praag, B. - Van der Sar, N. (1988): Household Cost Functions and Equivalence Scales. Journal of Human Resources, 23(2): 193-210.

PricewaterhouseCoopers (2015): Family Tax Reliefs and Benefits in the EU, https://www.pwc.pl/p1/ pdf/family-tax-reliefs-and-benefits-in-the-eu.pdf, Accessed on January 28, 2016.

Ree, de J. - Alessiez, R. - Pradhanx, M. (2013): The Price and Utility Dependence of Equivalence Scales: Evidence from Indonesia. Journal of Public Economics, 97: 272-281. 
Schokkaert, E. - Van Ootegemy, L. - Verhof, E. (2011): Preferences and Subjective Satisfaction: Measuring Well-Being on the Job for Policy Evaluation. CESifo Economic Studies, 57(4): 683714.

Schwarze, J. (2003): Using Panel Data on Income Satisfaction to Estimate Equivalence Scale Elasticity. Review of Income and Wealth, 49(3): 359-372.

Veenhoven, R. (2002): Why Social Policy Needs Subjective Indicators? Social Indicators Research, (11)58: 33-45.

Wooldridge, J. (2010): Econometric Analysis of Cross-Section and Panel Data. Cambridge: MIT Press. 


\section{APPENDIX}

Table A1. Information on economic and social situation in Poland, the Czech Republic, and Hungary

\begin{tabular}{l|c|c|c|c|c|c|c|c}
\hline & \multicolumn{2}{|c|}{ PL } & \multicolumn{2}{c|}{ HU } & \multicolumn{2}{c|}{ CZ } & \multicolumn{2}{c}{ EU15 } \\
\hline & 2005 & 2012 & 2005 & 2012 & 2005 & 2012 & 2005 & 2012 \\
\hline $\begin{array}{l}\text { GDP at market prices } \\
\text { (PPS per inhabitant) }\end{array}$ & 45.5 & 61.4 & 56.0 & 60.9 & 70.1 & 74.2 & 100.0 & 100.0 \\
\hline $\begin{array}{l}\text { Nominal labour productivity } \\
\text { per hour worked }\end{array}$ & 42.2 & 52.7 & 49.0 & 59.4 & 59.2 & 62.4 & 100.0 & 100.0 \\
\hline Share in gross value added & & & & & & & & \\
\hline $\begin{array}{l}\text { - Agriculture, forestry and } \\
\text { fishing }\end{array}$ & 3.7 & 3.2 & 5.04 & 4.63 & 2.55 & 2.38 & 1.82 & 1.50 \\
\hline - Manufacturing & 19.09 & 18.08 & 22.01 & 22.09 & 25.39 & 24.22 & 16.83 & 15.40 \\
\hline $\begin{array}{l}\text { - Wholesale and retail trade, } \\
\text { transport, accommodation, } \\
\text { and food }\end{array}$ & 25.18 & 25.12 & 17.49 & 18.09 & 20.40 & 18.20 & 19.28 & 18.65 \\
\hline - Construction & 6.45 & 8.72 & 5.36 & 4.14 & 6.62 & 6.17 & 6.01 & 5.57 \\
\hline $\begin{array}{l}\text { - Public administration, } \\
\text { defence, education, human } \\
\text { health, and social work } \\
\text { activities }\end{array}$ & 15.70 & 15.04 & 18.63 & 16.97 & 14.84 & 14.93 & 18.59 & 19.60 \\
\hline $\begin{array}{l}\text { - Professional, scientific, } \\
\text { and technical activities; } \\
\text { administrative }\end{array}$ & 6.29 & 6.95 & 7.96 & 9.06 & 6.48 & 6.55 & 10.02 & 10.55 \\
\hline $\begin{array}{l}\text { People at risk of poverty or } \\
\text { social exclusion (2) }\end{array}$ & $\mathrm{n} . \mathrm{a}$. & 26.7 & 32.1 & 33.5 & 19.6 & 15.4 & 21.7 & 23.1 \\
\hline $\begin{array}{l}\text { Total expenditure on social } \\
\text { protection as percentage of } \\
\text { GDP }\end{array}$ & 20.0 & 26.4 & 21.5 & 21.4 & 18.0 & 20.5 & 26.8 & 29.5 \\
\hline \begin{tabular}{l} 
HDI rank in 2015 (2) \\
\hline
\end{tabular} & $\mathrm{X}$ & 36 & $\mathrm{X}$ & 44 & $\mathrm{X}$ & 28 & $\mathrm{X}$ & $\mathrm{X}$ \\
\hline
\end{tabular}

Sources: Eurostat, Human Development Report 2015, UNDP, USA. 
Table A2. Observations by types of households for the 100 sample

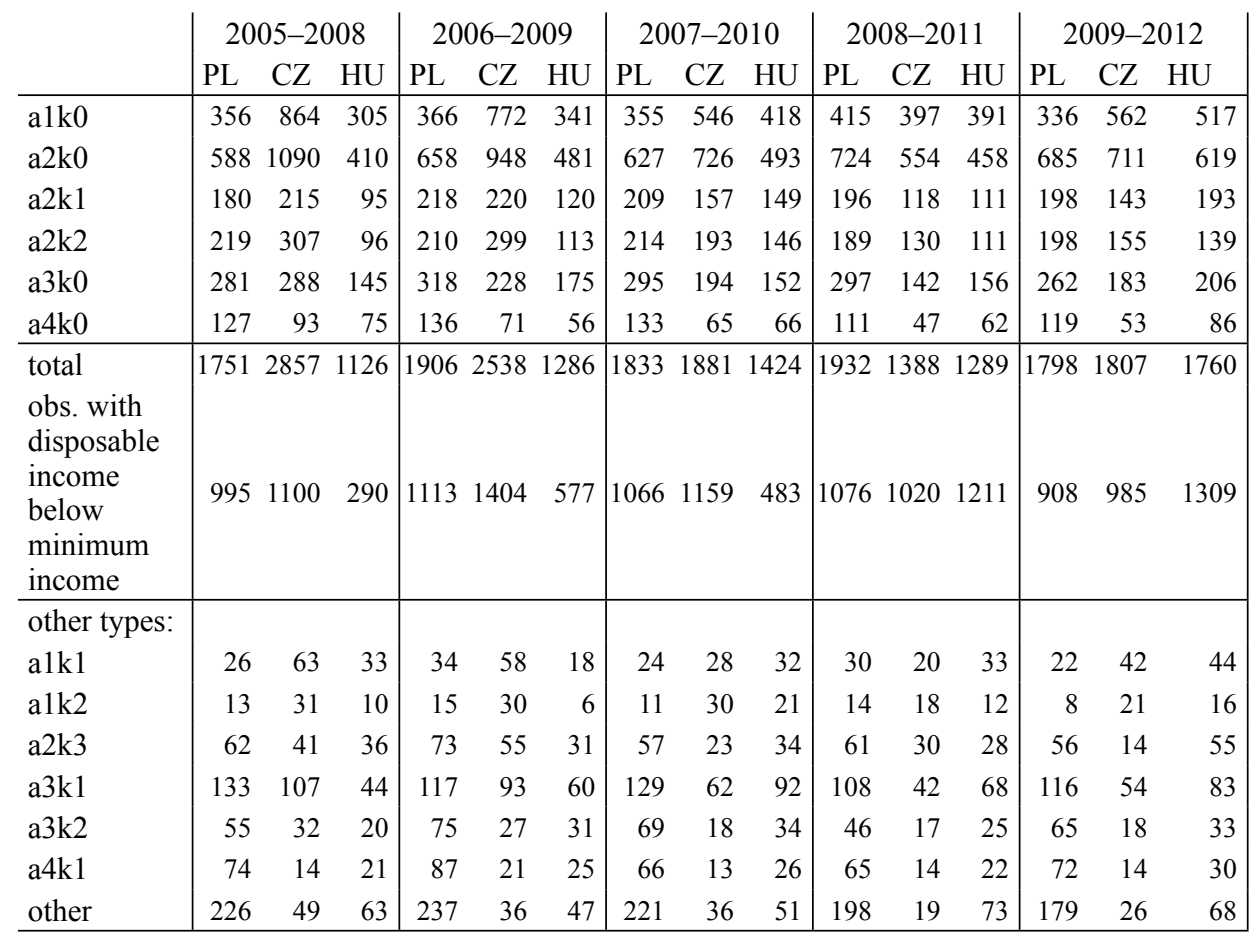

Note: Observations after removal of missing data in income variables. Counted for the first year of each panel wave. Source: Authors' calculations based on EU-SILC 2005-2012 data.

Table A3. Observations by types of households for the 25 sample

\begin{tabular}{l|rrr|rrr|rr|rr|rrr|rrr}
\hline & \multicolumn{2}{|c|}{$2005-2008$} & \multicolumn{2}{|c|}{$2006-2009$} & \multicolumn{2}{|c|}{$2007-2010$} & \multicolumn{2}{|c|}{ 2008-2011 } & \multicolumn{2}{|c}{ 2009-2012 } \\
& PL & CZ & HU & PL & CZ & HU & PL & CZ & HU & PL & CZ & HU & PL & CZ & HU \\
\hline a1k0 & 105 & 438 & 146 & 150 & 346 & 146 & 152 & 283 & 150 & 195 & 204 & 143 & 153 & 264 & 246 \\
a2k0 & 187 & 452 & 147 & 222 & 389 & 143 & 212 & 282 & 124 & 275 & 223 & 126 & 233 & 271 & 220 \\
a2k1 & 40 & 57 & 34 & 53 & 66 & 31 & 47 & 48 & 34 & 64 & 31 & 29 & 47 & 56 & 50 \\
a2k2 & 59 & 101 & 27 & 67 & 102 & 24 & 61 & 58 & 30 & 54 & 44 & 25 & 64 & 40 & 36 \\
a3k0 & 80 & 69 & 37 & 77 & 64 & 28 & 79 & 53 & 33 & 68 & 31 & 35 & 64 & 42 & 52 \\
a4k0 & 22 & 19 & 16 & 35 & 10 & 12 & 28 & 11 & 11 & 29 & 7 & 12 & 21 & 13 & 18 \\
\hline $\begin{array}{l}\text { total } \\
\text { obs. with dispos- } \\
\text { able income } \\
\text { below minimum } \\
\text { income }\end{array}$ & 493 & 1136 & 407 & 604 & 977 & 384 & 579 & 735 & 382 & 685 & 540 & 370 & 582 & 686 & 622 \\
\hline
\end{tabular}


Table A3. continued

\begin{tabular}{l|rrr|rr|rr|rr|rr|rrr|rr}
\hline & \multicolumn{2}{|c|}{$2005-2008$} & \multicolumn{2}{|c|}{$2006-2009$} & \multicolumn{2}{|c|}{$2007-2010$} & \multicolumn{2}{c|}{$2008-2011$} & \multicolumn{2}{c}{$2009-2012$} \\
& PL & CZ & HU & PL & CZ & HU & PL & CZ & HU & PL & CZ & HU & PL & CZ & HU \\
\hline other types: & & & & & & & & & & & & & \\
a1k1 & 6 & 22 & 14 & 8 & 20 & 5 & 8 & 9 & 2 & 11 & 8 & 9 & 9 & 9 & 17 \\
a1k2 & 4 & 11 & 3 & 7 & 14 & 1 & 3 & 10 & 7 & 3 & 6 & 8 & 2 & 12 & 5 \\
a2k3 & 13 & 25 & 11 & 24 & 19 & 11 & 19 & 5 & 13 & 26 & 14 & 7 & 19 & 5 & 18 \\
a3k1 & 32 & 24 & 9 & 22 & 27 & 10 & 33 & 19 & 21 & 37 & 13 & 15 & 29 & 19 & 19 \\
a3k2 & 17 & 8 & 8 & 20 & 14 & 10 & 18 & 4 & 7 & 12 & 5 & 6 & 18 & 7 & 5 \\
a4k1 & 15 & 2 & 6 & 15 & 10 & 5 & 17 & 2 & 7 & 17 & 4 & 5 & 10 & 7 & 7 \\
other & 50 & 11 & 18 & 60 & 11 & 8 & 58 & 8 & 9 & 51 & 5 & 19 & 38 & 5 & 12 \\
\hline
\end{tabular}

Note: Observations after removal of missing data in income variables. Counted for the first year of each panel wave.

Source: Authors' calculations based on EU-SILC 2005-2012 data.

Table A4. Households remaining in the same type of household for all the years of the panel for the 100 sample (\%)

\begin{tabular}{l|ccc|ccc|ccc|ccc|ccc|} 
& \multicolumn{2}{|c|}{$2005-2008$} & \multicolumn{2}{|c|}{$2006-2009$} & \multicolumn{3}{|c|}{$2007-2010$} & \multicolumn{3}{|c|}{$2008-2011$} & \multicolumn{3}{|c|}{$2009-2012$} \\
& PL & CZ & HU & PL & CZ & HU & PL & CZ & HU & PL & CZ & HU & PL & CZ & HU \\
\hline a1k0 & 0.92 & 0.94 & 0.93 & 0.95 & 0.95 & 0.93 & 0.94 & 0.95 & 0.95 & 0.94 & 0.95 & 0.95 & 0.94 & 0.94 & 0.95 \\
a1k1 & 0.54 & 0.54 & 0.58 & 0.47 & 0.53 & 0.61 & 0.58 & 0.54 & 0.59 & 0.53 & 0.55 & 0.42 & 0.59 & 0.60 & 0.59 \\
a1k2 & 0.38 & 0.58 & 0.50 & 0.33 & 0.53 & 0.33 & 0.27 & 0.50 & 0.43 & 0.50 & 0.56 & 0.50 & 0.63 & 0.62 & 0.38 \\
a2k0 & 0.84 & 0.85 & 0.78 & 0.79 & 0.85 & 0.79 & 0.82 & 0.83 & 0.78 & 0.80 & 0.86 & 0.80 & 0.85 & 0.82 & 0.83 \\
a2k1 & 0.58 & 0.56 & 0.56 & 0.56 & 0.52 & 0.63 & 0.55 & 0.49 & 0.54 & 0.58 & 0.41 & 0.50 & 0.54 & 0.53 & 0.65 \\
a2k2 & 0.60 & 0.67 & 0.70 & 0.65 & 0.67 & 0.65 & 0.63 & 0.66 & 0.62 & 0.62 & 0.67 & 0.58 & 0.65 & 0.67 & 0.67 \\
a2k3 & 0.52 & 0.59 & 0.58 & 0.56 & 0.67 & 0.65 & 0.60 & 0.43 & 0.65 & 0.52 & 0.63 & 0.61 & 0.48 & 0.29 & 0.51 \\
a3k0 & 0.57 & 0.70 & 0.66 & 0.63 & 0.69 & 0.78 & 0.61 & 0.69 & 0.68 & 0.61 & 0.65 & 0.71 & 0.66 & 0.69 & 0.69 \\
a3k1 & 0.29 & 0.34 & 0.34 & 0.33 & 0.38 & 0.28 & 0.40 & 0.35 & 0.41 & 0.35 & 0.31 & 0.43 & 0.38 & 0.39 & 0.30 \\
a3k2 & 0.40 & 0.31 & 0.30 & 0.37 & 0.33 & 0.35 & 0.35 & 0.33 & 0.56 & 0.35 & 0.35 & 0.32 & 0.45 & 0.50 & 0.21 \\
a4k0 & 0.42 & 0.65 & 0.52 & 0.55 & 0.72 & 0.43 & 0.38 & 0.63 & 0.48 & 0.45 & 0.70 & 0.66 & 0.47 & 0.70 & 0.64 \\
a4k1 & 0.32 & 0.36 & 0.52 & 0.49 & 0.29 & 0.40 & 0.38 & 0.23 & 0.35 & 0.22 & 0.14 & 0.14 & 0.35 & 0.21 & 0.33 \\
other & 0.69 & 0.57 & 0.57 & 0.67 & 0.72 & 0.77 & 0.69 & 0.44 & 0.80 & 0.74 & 0.58 & 0.70 & 0.70 & 0.73 & 0.74 \\
\hline
\end{tabular}

Source: Authors' calculations based on EU-SILC 2005-2012 data. 
Table A5. Households remaining in the same type of household for all the years of the panel for the 25 sample (\%)

\begin{tabular}{l|ccc|ccc|ccc|ccc|ccc} 
& \multicolumn{3}{|c|}{$2005-2008$} & \multicolumn{3}{|c|}{$2006-2009$} & \multicolumn{3}{|c|}{$2007-2010$} & \multicolumn{3}{|c|}{$2008-2011$} & \multicolumn{3}{|c}{$2009-2012$} \\
& PL & CZ & HU & PL & CZ & HU & PL & CZ & HU & PL & CZ & HU & PL & CZ & HU \\
\hline a1k0 & 0.92 & 0.95 & 0.97 & 0.97 & 0.97 & 0.95 & 0.99 & 0.98 & 0.94 & 0.96 & 0.98 & 0.96 & 0.96 & 0.98 & 0.97 \\
a1k1 & 0.67 & 0.45 & 0.57 & 0.38 & 0.60 & 0.40 & 0.50 & 0.44 & 0.50 & 0.27 & 0.75 & 0.44 & 0.33 & 0.56 & 0.47 \\
a1k2 & 0.00 & 0.55 & 0.67 & 0.29 & 0.43 & 0.00 & 0.00 & 0.60 & 0.43 & 0.33 & 0.33 & 0.63 & 0.50 & 0.67 & 0.40 \\
a2k0 & 0.86 & 0.90 & 0.77 & 0.82 & 0.87 & 0.85 & 0.86 & 0.86 & 0.79 & 0.83 & 0.85 & 0.79 & 0.89 & 0.82 & 0.85 \\
a2k1 & 0.65 & 0.61 & 0.53 & 0.51 & 0.50 & 0.74 & 0.53 & 0.44 & 0.50 & 0.48 & 0.45 & 0.41 & 0.55 & 0.57 & 0.66 \\
a2k2 & 0.73 & 0.69 & 0.52 & 0.58 & 0.73 & 0.50 & 0.62 & 0.64 & 0.80 & 0.65 & 0.64 & 0.72 & 0.69 & 0.73 & 0.61 \\
a2k3 & 0.62 & 0.68 & 0.45 & 0.46 & 0.63 & 0.45 & 0.53 & 0.60 & 0.62 & 0.50 & 0.57 & 0.71 & 0.47 & 0.20 & 0.56 \\
a3k0 & 0.54 & 0.65 & 0.68 & 0.68 & 0.72 & 0.71 & 0.62 & 0.68 & 0.61 & 0.65 & 0.74 & 0.71 & 0.73 & 0.64 & 0.63 \\
a3k1 & 0.25 & 0.38 & 0.00 & 0.45 & 0.48 & 0.30 & 0.52 & 0.32 & 0.62 & 0.32 & 0.38 & 0.53 & 0.31 & 0.37 & 0.32 \\
a3k2 & 0.35 & 0.38 & 0.25 & 0.35 & 0.36 & 0.20 & 0.22 & 0.50 & 0.71 & 0.25 & 0.40 & 0.33 & 0.44 & 0.57 & 0.20 \\
a4k0 & 0.50 & 0.47 & 0.56 & 0.51 & 0.70 & 0.42 & 0.36 & 0.64 & 0.64 & 0.52 & 0.57 & 0.67 & 0.48 & 0.69 & 0.67 \\
a4k1 & 0.33 & 0.50 & 0.67 & 0.27 & 0.40 & 0.60 & 0.35 & 0.00 & 0.43 & 0.29 & 0.25 & 0.00 & 0.20 & 0.14 & 0.29 \\
other & 0.70 & 0.73 & 0.61 & 0.67 & 0.91 & 0.88 & 0.60 & 0.50 & 0.89 & 0.78 & 0.60 & 0.74 & 0.66 & 0.80 & 0.75 \\
\hline
\end{tabular}

Source: Authors' calculations based on EU-SILC 2005-2012 data.

Table A6. Values of statistics $\mathrm{F}$ in the Wooldridge test for insignificance of the correlation between the individual effect and regressors

\begin{tabular}{l|crc} 
& PL & CZ & HU \\
\hline Model 25 & 1863.07 & 1461.67 & 424.44 \\
Model 100 & 1245.44 & 811.42 & 554.48 \\
\hline
\end{tabular}

Sources: Wooldridge (2010: 280-281). Authors' calculations based on EU-SILC 2005-2012 data.

Table A7. Results of regression for the 25 sample (2005-2012)

\begin{tabular}{|c|c|c|c|c|c|c|}
\hline \multirow[b]{2}{*}{ Variable } & \multicolumn{2}{|c|}{ PL25 } & \multicolumn{2}{|c|}{$\mathrm{CZ25}$} & \multicolumn{2}{|c|}{ HU25 } \\
\hline & OLS & $\mathrm{FE}$ & OLS & FE & OLS & $\mathrm{FE}$ \\
\hline Income & $0.7681 * * *$ & $0.2736^{* * *}$ & $0.7451 * * *$ & $0.2783 * * *$ & $0.7067 * * *$ & $0.3294 * * *$ \\
\hline $\mathrm{a} 2 \mathrm{k} 0$ & $0.0955^{* * *}$ & $0.2752 * * *$ & $0.1063 * * *$ & $0.3062 * * *$ & $0.1301 * * *$ & $0.2397 * * *$ \\
\hline $\mathrm{a} 3 \mathrm{k} 0$ & $0.1594 * * *$ & $0.4227 * * *$ & $0.1950 * * *$ & $0.4290 * * *$ & $0.1830 * * *$ & $0.3448 * * *$ \\
\hline $\mathrm{a} 4 \mathrm{k} 0$ & $0.1545^{* * *}$ & $0.4342 * * *$ & $0.2331 * * *$ & $0.4985 * * *$ & $0.2518 * * *$ & $0.4947 * * *$ \\
\hline $\mathrm{a} 2 \mathrm{k} 1$ & $0.1404 * * *$ & $0.4166^{* * *}$ & $0.1898 * * *$ & $0.4279 * * *$ & $0.2089 * * *$ & $0.3016^{* * *}$ \\
\hline $\mathrm{a} 2 \mathrm{k} 2$ & $0.1689 * * *$ & $0.4336^{* * *}$ & $0.1946^{* * *}$ & $0.4615 * * *$ & $0.2182 * * *$ & $0.3353 * * *$ \\
\hline 2006 & $-0.0367^{*}$ & $0.0360^{*}$ & $0.0314 * * *$ & $0.0730 * * *$ & $0.0277^{*}$ & $0.0492 * * *$ \\
\hline 2007 & -0.0380 * & $0.0636^{* * *}$ & $0.0444 * * *$ & $0.1351 * * *$ & $-0.0512 * * *$ & -0.0194 \\
\hline 2008 & $-0.0411^{*}$ & $0.0976^{* * *}$ & $0.0643 * * *$ & $0.1636^{* * *}$ & $0.1015 * * *$ & $0.1551 * * *$ \\
\hline 2009 & -0.0331 & $0.1593 * * *$ & $0.0796^{* * *}$ & $0.2357 * * *$ & $0.1017 * * *$ & $0.1873 * * *$ \\
\hline 2010 & $-0.0788 * * *$ & 0.0207 & $0.0608 * * *$ & $0.1950 * * *$ & $0.1082 * * *$ & $0.1454 * * *$ \\
\hline
\end{tabular}


Table A7. continued

\begin{tabular}{l|cc|cc|cc|}
\hline & \multicolumn{2}{|c|}{ PL25 } & \multicolumn{2}{c|}{ CZ25 } & \multicolumn{2}{c|}{ HU25 } \\
Variable & OLS & FE & OLS & FE & OLS & FE \\
\hline 2011 & $-0.0555^{* *}$ & $0.0961^{* * *}$ & $0.0675^{* * *}$ & $0.2179^{* * *}$ & -0.0204 & 0.0037 \\
2012 & $-0.0740^{* * *}$ & $0.0603^{* *}$ & $0.0718^{* * *}$ & $0.2427 * * *$ & -0.0031 & 0.0270 \\
Cons & $1.9010^{* * *}$ & $5.8713^{* * *}$ & $2.0634^{* * *}$ & $5.9620^{* * *}$ & $2.2882^{* * *}$ & $5.3782 * * *$ \\
& & & & & & \\
N & 11699 & 11699 & 16197 & 16197 & 8540 & 8540 \\
r2_a & 0.7838 & 0.2687 & 0.8213 & 0.2902 & 0.7432 & 0.2947 \\
Corr. & & 0.4344 & & 0.5015 & & 0.4440 \\
sigma_u & & 0.2657 & & 0.2078 & & 0.2010 \\
sigma_e & & 0.1826 & & 0.1592 & & 0.2057 \\
\hline
\end{tabular}

Notes: Sample limited to observations for which the relative difference between the minimum income and disposable income is less than $25 \%$. Standard deviations of the FE estimator were calculated while controlling for the possible correlation of an individual random error in time. *: significant at a significance level of 5\%, $* *$ : significant at a significance level of $1 \%,{ }^{* * *}$ : significant at a significance level of $0.1 \%$.

Source: Wooldridge (2010: 280-281). Authors' calculations based on EU-SILC 2005-2012 data.

Table A8. Results of regression for the 100 sample (2005-2012)

\begin{tabular}{|c|c|c|c|c|c|c|}
\hline \multirow[b]{2}{*}{ Variable } & \multicolumn{2}{|c|}{ PL100 } & \multicolumn{2}{|c|}{$\mathrm{CZ100}$} & \multicolumn{2}{|c|}{ HU100 } \\
\hline & POLS & $\mathrm{FE}$ & POLS & $\mathrm{FE}$ & POLS & $\mathrm{FE}$ \\
\hline Income & $0.4147 * * *$ & $0.1072 * * *$ & $0.3685 * * *$ & $0.0989 * * *$ & $0.3683 * * *$ & $0.1002 * * *$ \\
\hline $\mathrm{a} 2 \mathrm{k} 0$ & $0.1702 * * *$ & $0.3063 * * *$ & $0.2035^{* * *}$ & $0.2749 * * *$ & $0.2082 * * *$ & $0.2246^{* * *}$ \\
\hline $\mathrm{a} 3 \mathrm{k} 0$ & $0.2680 * * *$ & $0.4345 * * *$ & $0.3059 * * *$ & $0.3905^{* * *}$ & $0.3199 * * *$ & $0.3868 * * *$ \\
\hline $\mathrm{a} 4 \mathrm{k} 0$ & $0.2969 * * *$ & $0.4930 * * *$ & $0.3904 * * *$ & $0.4741 * * *$ & $0.4451 * * *$ & $0.5050 * * *$ \\
\hline a2k1 & $0.2538 * * *$ & $0.4259 * * *$ & $0.3499 * * *$ & $0.3494 * * *$ & $0.3407 * * *$ & $0.3287 * * *$ \\
\hline $\mathrm{a} 2 \mathrm{k} 2$ & $0.3094 * * *$ & $0.5037 * * *$ & $0.3891 * * *$ & $0.3990 * * *$ & $0.3856^{* * *}$ & $0.3916^{* * *}$ \\
\hline 2006 & 0.0015 & $0.0665 * * *$ & $0.0589 * * *$ & $0.0886^{* * *}$ & $0.0648 * * *$ & $0.0931 * * *$ \\
\hline 2007 & 0.0093 & $0.1031 * * *$ & $0.1100 * * *$ & $0.1702 * * *$ & $-0.1062 * * *$ & $-0.0357^{*}$ \\
\hline 2008 & $0.0272 *$ & $0.1497 * * *$ & $0.1417 * * *$ & $0.2060 * * *$ & $0.1184 * * *$ & $0.1994 * * *$ \\
\hline 2009 & $0.0375^{* *}$ & $0.2082 * * *$ & $0.1901 * * *$ & $0.2994 * * *$ & $0.1682 * * *$ & $0.2871 * * *$ \\
\hline 2010 & $-0.0816^{* * *}$ & $0.0350 * *$ & $0.1524 * * *$ & $0.2490 * * *$ & $0.1318 * * *$ & $0.2292 * * *$ \\
\hline 2011 & $-0.0260^{*}$ & $0.1202 * * *$ & $0.1857 * * *$ & $0.2870 * * *$ & $-0.0678 * * *$ & 0.0160 \\
\hline 2012 & $-0.0544 * * *$ & $0.0896 * * *$ & $0.1977 * * *$ & $0.3195 * * *$ & $-0.0699 * * *$ & 0.0272 \\
\hline Cons. & $4.8097 * * *$ & $7.2707 * * *$ & $5.2148 * * *$ & $7.5380 * * *$ & $5.0617 * * *$ & $7.2902 * * *$ \\
\hline $\mathrm{N}$ & 36481 & 36481 & 41317 & 41317 & 26946 & 26946 \\
\hline r2_a & 0.4710 & 0.1441 & 0.4957 & 0.1509 & 0.4433 & 0.1826 \\
\hline Corr. & & 0.1883 & & 0.3253 & & 0.2690 \\
\hline sigma_u & & 0.3296 & & 0.3005 & & 0.2951 \\
\hline sigma_e & & 0.2423 & & 0.2067 & & 0.3010 \\
\hline
\end{tabular}

Note: Standard deviations of the FE estimator were calculated while controlling for the possible correlation of an individual random error in time. $*$ : significant at a significance level of $5 \%, * *$ : significant at a significance level of $1 \%, * * *$ : significant at a significance level of $0.1 \%$.

Source: Authors' calculations based on EU-SILC 2005-2012 data.

Table A9. Equivalent scales calculated after the FE and OLS estimations with confidence intervals 


\begin{tabular}{|c|c|c|c|c|c|c|c|c|c|c|c|c|c|}
\hline & \multicolumn{3}{|c|}{ PL } & \multicolumn{3}{|c|}{$\mathrm{CZ}$} & \multicolumn{3}{|c|}{ HU } & \multirow{2}{*}{\multicolumn{2}{|c|}{$D\left|\begin{array}{c}\text { Square } \\
\text { root }\end{array}\right|$}} & \multirow{2}{*}{$\begin{array}{l}\text { Bish- } \\
\text { op }\end{array}$} \\
\hline & & CIL & CI & CIU & CIL & CI & CIU & CIL & CI & $\mathrm{CIU}$ & & & \\
\hline \multirow{6}{*}{$\begin{array}{l}\text { సิ } \\
\text { స్․ }\end{array}$} & a1k0 & 1.000 & 1.000 & 1.000 & 1.000 & 1.000 & 1.000 & 1.000 & 1.000 & 1.000 & 1.000 & \begin{tabular}{|l|}
1.000 \\
\end{tabular} & $\mathrm{X}$ \\
\hline & $\mathrm{a} 2 \mathrm{k} 0$ & 1.339 & 1.461 & 1.582 & 456 & 1.528 & 1.601 & 1.331 & 1.430 & 1.528 & 1.500 & 1.414 & $X$ \\
\hline & a2k1 & 1.541 & 1.775 & 2.008 & 1.669 & 1.809 & 1.949 & 1.351 & 1.568 & 1.785 & 1.800 & 1.732 & $\mathrm{X}$ \\
\hline & $\mathrm{a} 3 \mathrm{k} 0$ & 1.602 & 1.789 & 1.977 & 1.648 & 1.812 & 1.976 & 1.460 & 1.672 & 1.884 & 2.000 & 1.732 & $X$ \\
\hline & a $2 \mathrm{k} 2$ & 1.532 & 1.816 & 2.101 & 1.717 & 1.895 & 2.074 & 1.350 & 1.649 & 1.948 & 2.100 & 2.000 & $\mathrm{X}$ \\
\hline & $\mathrm{a} 4 \mathrm{k} 0$ & 1.532 & 1.818 & 2.104 & 1.737 & 1.995 & 2.254 & 1.713 & 2.091 & 2.469 & 2.500 & 2.000 & $X$ \\
\hline \multirow{6}{*}{$\frac{8}{8}$} & alk0 & 1.000 & 0 & 1.000 & 000 & 1.000 & 1.000 & 1.000 & 1.000 & 1.000 & 1.000 & 1.000 & $X$ \\
\hline & $\mathrm{a} 2 \mathrm{k} 0$ & 1.353 & 1.409 & 1.466 & 1.310 & 1.357 & 1.403 & 1.222 & 1.284 & 1.345 & 1.500 & 1.414 & $\mathrm{X}$ \\
\hline & a2k1 & 1.519 & 1.611 & 1.704 & 1.389 & 1.474 & 1.558 & 1.323 & 1.441 & 1.559 & 1.800 & 1.732 & $X$ \\
\hline & $\mathrm{a} 3 \mathrm{k} 0$ & 1.547 & 1.627 & 1.707 & 1.464 & 1.542 & 1.621 & 1.429 & 1.537 & 1.645 & 2.000 & 1.732 & $\mathrm{X}$ \\
\hline & $\mathrm{a} 2 \mathrm{k} 2$ & 1.633 & 1.758 & 1.882 & 1.460 & 1.557 & 1.654 & 1.376 & 1.545 & 1.714 & 2.100 & 2.000 & $\mathrm{X}$ \\
\hline & $\mathrm{a} 4 \mathrm{k} 0$ & 1.624 & 1.737 & 1.850 & 1.568 & 1.692 & 1.817 & 1.599 & 1.753 & 1.906 & 2.500 & 2.000 & $X$ \\
\hline \multirow{6}{*}{$\begin{array}{l}\text { â } \\
\text { के } \\
0 \\
0\end{array}$} & alk0 & 1.000 & 1.000 & 1.000 & 1.000 & 1.000 & 1.000 & 1.000 & 1.000 & 1.000 & 1.000 & 1.000 & $X$ \\
\hline & $\mathrm{a} 2 \mathrm{k} 0$ & 1.434 & 1.509 & 1.584 & 1.461 & 1.517 & 1.574 & 1.492 & 1.558 & 1.624 & 1.500 & 1.414 & $\mathrm{X}$ \\
\hline & a2k1 & 1.600 & 1.832 & 2.064 & 1.975 & 2.106 & 2.237 & 1.886 & 2.038 & 2.191 & 1.800 & 1.732 & $X$ \\
\hline & $\mathrm{a} 3 \mathrm{k} 0$ & 1.847 & 1.989 & 2.130 & 2.005 & 2.149 & 2.293 & 1.722 & 1.866 & 2.011 & 2.000 & 1.732 & $X$ \\
\hline & $\mathrm{a} 2 \mathrm{k} 2$ & 1.895 & 2.072 & 2.249 & 2.019 & 2.146 & 2.272 & 1.907 & 2.105 & 2.302 & 2.100 & 2.000 & $X$ \\
\hline & $\mathrm{a} 4 \mathrm{k} 0$ & 1.700 & 1.947 & 2.194 & 2.201 & 2.495 & 2.790 & 2.085 & 2.360 & 2.634 & 2.500 & 2.000 & $X$ \\
\hline \multirow{6}{*}{$\begin{array}{l}8 \\
0 \\
01 \\
0\end{array}$} & a1k0 & 1.000 & 1.000 & 1.000 & 1.000 & 1.000 & 1.000 & 1.000 & 1.000 & 1.000 & 1.000 & 1.000 & 1.00 \\
\hline & $\mathrm{a} 2 \mathrm{k} 0$ & 1.311 & 1.338 & 1.364 & 1.359 & 1.380 & 1.401 & 1.363 & 1.390 & 1.418 & 1.500 & 1.414 & 1.34 \\
\hline & $\mathrm{a} 2 \mathrm{k} 1$ & 1.497 & 1.543 & 1.589 & 1.698 & 1.740 & 1.783 & 1.647 & 1.715 & 1.782 & 1.800 & 1.732 & 1.64 \\
\hline & $\mathrm{a} 3 \mathrm{k} 0$ & 1.541 & 1.581 & 1.620 & 1.582 & 1.623 & 1.664 & 1.613 & 1.659 & 1.705 & 2.000 & 1.732 & 1.52 \\
\hline & $\mathrm{a} 2 \mathrm{k} 2$ & 1.648 & 1.697 & 1.745 & 1.811 & 1.852 & 1.892 & 1.778 & 1.841 & 1.904 & 2.100 & 2.000 & 1.78 \\
\hline & $\mathrm{a} 4 \mathrm{k} 0$ & 1.605 & 1.661 & 1.716 & 1.790 & 1.856 & 1.922 & 1.943 & 2.023 & 2.103 & 2.500 & 2.000 & 1.73 \\
\hline
\end{tabular}

Source: Authors' calculations based on the EU-SILC 2005-2012 data. 